\title{
Effectiveness of fortification of corn flour-derived products with hydrogen-reduced elemental iron on iron-deficiency anaemia in children and adolescents in southern Brazil
}

\author{
Lúcia HS Miglioranza ${ }^{1, *}$, José Wander Breganó ${ }^{2}$, Isaias Dichi ${ }^{3}$, Tiemi Matsuo ${ }^{4}$, \\ Jane Bandeira Dichi ${ }^{3}$ and Décio Sabbatini Barbosa ${ }^{2}$ \\ 'Department of Food Science and Technology, University of Londrina, Campus Universitário, Rod. Celso Garcia \\ Cid., PO Box 6001, Londrina, Paraná, Brazil: ²Department of Pathology, Clinical Analysis and Toxicology, \\ University of Londrina, Londrina, Brazil: ${ }^{3}$ Department of Internal Medicine, University of Londrina, Londrina, \\ Brazil: ${ }^{4}$ Department of Statistics and Applied Mathematics, University of Londrina, Londrina, Brazil
}

Submitted 19 March 2008: Accepted 18 August 2008: First published online 15 September 2008

\begin{abstract}
Objective: To find the ideal combination of Fe fortifier and its food vehicle is an essential measure in developing countries. However, its cost also plays an important role. In the present study, the effect on blood parameter values of corn flour-derived products fortified with powdered elemental $\mathrm{Fe}$ in the form of $\mathrm{H}_{2}$-reduced $\mathrm{Fe}$ was investigated in children and adolescents.

Methods: One hundred and sixty-two individuals (eighty-six boys and seventy-six girls) from public educational centres in Londrina, Paraná (southern Brazil) participated in the study. Fe-deficiency anaemia (IDA) was defined when $\mathrm{Hb}$ and serum ferritin values fell below $12 \mathrm{~g} / \mathrm{dl}$ and $20 \mu \mathrm{g} / \mathrm{l}$, respectively; Fe deficiency (ID) was considered when serum ferritin was below $20 \mu \mathrm{g} / \mathrm{l}$.

Results: The prevalence of ID and IDA decreased from $18 \cdot 0 \%$ and $14 \cdot 9 \%$, values found at the beginning of the study, to respectively $5 \cdot 6 \%$ and $1 \cdot 2 \%$ after 6 months. Changes from altered to normal values occurred more often than normal to altered values with transferrin saturation $(14 \cdot 2 \% v \cdot 6 \cdot 8 \% ; P<0 \cdot 04)$ and ferritin $(12 \cdot 4 \% v .0 \% ; P<0 \cdot 001)$. $\mathrm{Hb}$, transferrin saturation and ferritin showed differences between normal and altered parameters after 6 months $(P<0 \cdot 001)$. Conclusion: A pronounced reduction in the prevalence of ID and IDA was observed in children and adolescents following 6 months' ingestion of corn flour-derived products enriched with elemental Fe.
\end{abstract}

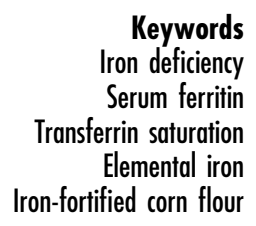

Fe deficiency (ID) is the most common nutritional deficiency disorder in the world, affecting more than two billion people, mostly infants, children and women of childbearing age ${ }^{(1)}$.

In general, the symptoms of ID are considered to be due probably not to lowered $\mathrm{Hb}$ level, but to an insufficient supply of Fe to the tissues ${ }^{(2)}$. The human brain develops up until about 20 years of age, and brain Fe content also increases concomitantly up to this age. It may be difficult to repair the negative effects of ID developed during this period ${ }^{(2)}$. It may therefore be assumed that optimal Fe adequacy should prevail in an individual at least during the first 20 years of life ${ }^{(2)}$. Several reviews ${ }^{(3,4)}$ and recent reports ${ }^{(5,6)}$ show negative effects of ID related to mental symptoms in infants and children, but unrelated to anaemia; even in adolescents there exist concerns on this issue ${ }^{(7)}$. Therefore, the outcome of current evidence strongly suggests that to assure optimal health and development, it is important to prevent and treat even mild ID of growing individuals, at least up to around 20 years of age, as well as during pregnancy $^{(2)}$.

Fortification of food with $\mathrm{Fe}$, when an appropriate diet is not available, is considered the best sustainable way of preventing ID. The most difficult challenge to this end is to find the ideal combination of an Fe-fortified compound and its corresponding food vehicle ${ }^{(8)}$.

There exist many reports on the successful addition of NaFeEDTA or Fe(II) bisglycinate fortifiers in the form of an Fe chelate, which protects from combination with dietary inhibitors, mainly phytic $\operatorname{acid}^{(8)}$. Furthermore, little evidence exists that Fe fortification of staple foods, such as corn flour, is a useful strategy to combat ID $^{(9)}$. Theoretically, it could be assumed that elemental $\mathrm{Fe}$ as a fortifier and corn flour as food vehicle would not be a really ideal combination. Concern exists about using this 
combination in phytate-rich diets, and diet in the poorer areas of Brazil is basically composed of rice, beans and vegetables.

However, it could be argued that reports on $\mathrm{Fe}$ absorption were verified with single meals, under special conditions, and that studies in which the effects of enhancers and inhibitors of Fe absorption were studied in whole meals showed results that were far less pronounced than those from single meals ${ }^{(10,11)}$. Fortification of cereal flour with elemental $\mathrm{Fe}$ was successful in Chile $^{(12)}$. Aside from these considerations, it should be emphasized that costs are very important in fortification measures, especially to convince political authorities in developing countries of the need for a continued $\mathrm{Fe}$ fortification programme.

The aim of the present study, therefore, was to investigate the effect of corn flour-derived products fortified with elemental Fe on ID and Fe-deficiency anaemia (IDA) prevalence in children and adolescents assisted by public educational centres in Londrina, Brazil.

\section{Material and methods}

The assessed population participated in public educational centres in Londrina, Parana State (southern Brazil), which assist families living under precarious socioeconomic conditions. Their annual income is less than \$US 2000.00 per capita; $85 \%$ of the children's parents have not more than 3-4 years of schooling. The evaluation study took place in nine peripheral city centres and was sponsored by the local city government; for $6 \mathrm{~h}$ each day, the centres provided recreation, pedagogic assistance, cultural activities and meals for children below 14 years of age. In most cases, meals provided at these centres are this population's only access to food. It is important to mention that the population studied did not receive supplements from any government programme and had no involvement with any organization or entity with policy interest in the matter.

The Ethical Committee of the University of Londrina approved the study, and the children's parents signed formal agreements to it.

All children and adolescents (362 subjects) from the nine peripheral city centres were recruited to participate in the study. Blood samples were collected by venepuncture from individuals who had fasted for $12 \mathrm{~h}$. The following parameters were assessed: $\mathrm{Hb}$, measured by an automated counter (Pentra 120 Retic; ABX-Horiba, Montpellier, France); percentage transferrin saturation $(100 \times$ serum Fe/total Febinding capacity), estimated by the Ferrozine method using an automatic chemistry analyser (Dimension AR; DadeBehring, Deerfield, IL, USA); and serum ferritin, estimated by the microparticle enzyme immunoassay method using an automatic immunoassay analyser (AxSYM; Abbott, Irving, TX, USA). The children and adolescents were assessed at the beginning of the study (baseline) and after 6 months of treatment, and only data for the 162 individuals (eighty-six boys and seventy-six girls, age range 7-14 years) from whom blood samples were obtained at baseline and after 6 months are presented. IDA was so defined when $\mathrm{Hb}$ level lower than $12 \mathrm{~g} / \mathrm{dl}$ and serum ferritin level lower than $20 \mu \mathrm{g} / 1$ were found, and ID when serum ferritin had fallen to less than $20 \mu \mathrm{g} / \mathrm{l}$. The value used to express alteration in the other assessed parameter was transferrin saturation $\leq 16 \%$. Children and adolescents with clinically evident infection or inflammation, at the beginning and the end of the study, were excluded to avoid interference with the acute-phase reactant proteins serum ferritin and transferrin.

Fortification was accomplished by administering corn flour-derived sweet and salty products (biscuits, cakes and pies), fortified with elemental $\mathrm{Fe}$ powder in the form of $\mathrm{H}_{2}$-reduced $\mathrm{Fe}(<45 \mu \mathrm{m}$ or 325 mesh). The corn flour-derived products had been previously evaluated and found to have an excellent acceptance. Each subject ingested daily $100 \mathrm{~g}$ of the corn flour-derived products, containing $76 \mathrm{~g}$ carbohydrates, $2 \mathrm{~g}$ fat, $8 \mathrm{~g}$ protein, $9.8 \mathrm{mg}$ Fe and $0.35 \mathrm{mg}$ folic acid.

Changes in blood parameters occurring during the study were estimated relative to baseline values, using the McNemar test for paired data. Differences (means and standard deviations, medians) between normal and altered blood parameters were calculated at the end of the study using the Mann-Whitney test. Differences showing $P$ values of $<0 \cdot 05$ found respectively prior to and following treatment were considered to be statistically significant.

\section{Results}

The prevalence of ID and IDA at the beginning of the study was $18.0 \%$ and $14.9 \%$, respectively; a reduction to $5 \cdot 6 \%$ and $1 \cdot 2 \%$, respectively, was observed after 6 months of Fe fortification (Fig. 1).

Statistically significant changes from altered to normal values occurred more often than normal to altered values with transferrin saturation $(14 \cdot 2 \% v \cdot 6 \cdot 8 \% ; P<0 \cdot 04)$ and ferritin (12.4\% v. 0\%; $P<0 \cdot 001$; Table 1$)$.

All blood parameters (mean and SD, median) showed statistically significant differences between altered and normal levels after 6 months $(P<0 \cdot 001$; Table 2$)$. Altered transferrin saturation and serum ferritin increased from 10.9 (sD 3.8) $\%$ and 13.2 (SD 4.1) $\mu \mathrm{g} / \mathrm{l}$ before fortification to $26 \cdot 4$ (sD $10 \cdot 9$ ) $\%$ and $25 \cdot 5$ (SD $10 \cdot 8$ ) $\mu \mathrm{g} / \mathrm{l}$, respectively, after fortification.

\section{Discussion}

In the present study, $14.9 \%$ of the subjects had anaemia. It must be emphasized that a previous study at the same environmental outskirts' educational centres showed initial anaemia prevalence of $41.9 \%$ and, after 1 year of 
fortification with $\mathrm{Fe}(\mathrm{II})$ bisglycinate, a final prevalence of $9 \cdot 6 \%{ }^{(13)}$. Echoes of that long-term intervention study certainly still remained.

There was a high decrease in the number of subjects studied in the present study. The main reasons were the presence of infection or inflammation near the end of the study and dropout due mainly to socio-economic reasons. However, the number of subjects who dropped out was relatively proportional in all nine public educational centres.

Elemental Fe powders are the most common Fe fortifiers used worldwide, since they cause the least problems concerning colour, flavour and rancidity in food products and are in general less expensive. However, many concerns about their utilization remain ${ }^{(8,14)}$. First, there is little evidence that they have a beneficial effect on Fe status. Second, powdered elemental $\mathrm{Fe}$ is water-insoluble and poorly soluble in dilute acids; thus, because it never dissolves completely in the gastric juice, it has a low and variable bioavailability, ranging from $5 \%$ to $148 \%$ relative to standard $\mathrm{FeSO}_{4}$. Third, powders with large particle size $(>149 \mu \mathrm{m}$ or 100 mesh) interfere negatively with Fe absorption.

There are five different types of elemental Fe powders used for food fortification: (i) electrolytically reduced;

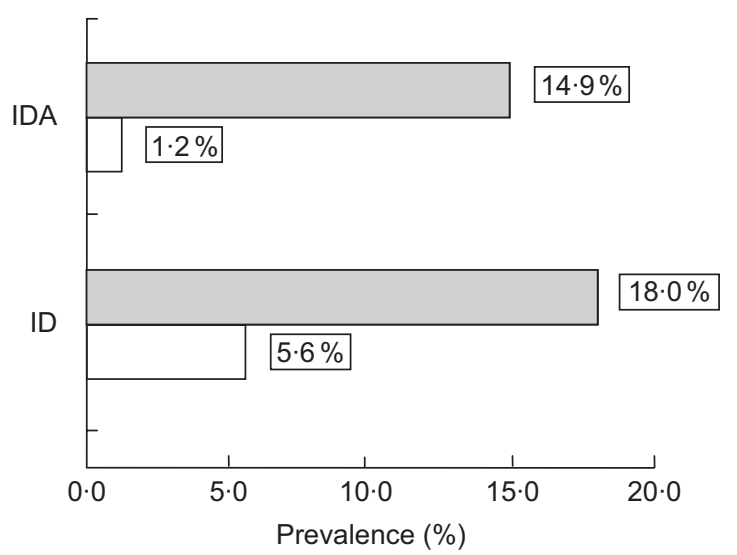

Fig. 1 Iron deficiency (ID) and iron-deficiency anaemia (IDA) prevalence in Brazilian children and adolescents at the beginning of the study $(\square)$ and following 6 months of treatment $(\square)$ with corn flour-derived products fortified with powdered elemental iron in the form of hydrogen-reduced iron (ii) $\mathrm{H}_{2}$-reduced; (iii) CO-reduced; (iv) atomized (reduced); and (v) carbonyl-Fe. In a study of Fe absorption measured with ${ }^{58} \mathrm{Fe}$ in ten non-anaemic female volunteers with fairly low Fe stores, Roe and Fairwheather-Tait ${ }^{(15)}$ verified that $\mathrm{H}_{2}$-reduced $\mathrm{Fe}$ powder compares favourably with the absorption of well-absorbed $\mathrm{Fe}$ (Fe(II) ascorbate) and reinforced the current use of reduced Fe powder to fortify flour in the UK. García-Casal et $a l^{(16)}$ also found that $\mathrm{H}_{2}$-reduced Fe-fortified cereal had a significantly higher absorption rate than cereal without Fe fortification $(9 \cdot 27$ and $3 \cdot 38$, respectively). Fe content of the corn flakes was $3.5 \mathrm{mg} / 30 \mathrm{mg}$, a content of $\mathrm{H}_{2}$-reduced $\mathrm{Fe}$ similar to that used in the present study $(9 \cdot 8 \mathrm{mg} / 100 \mathrm{~g})$. On the other hand, Walter et al. ${ }^{(17)}$ found that $\mathrm{H}_{2}$-reduced $\mathrm{Fe}$ powder at $3 \mathrm{mg} / 100 \mathrm{~g}$ was ineffective as a fortifier in corn tortillas prepared with corn masa flour given to 5- to 7-year-old children.

However, an expert panel ${ }^{(18)}$ reporting on the usefulness of elemental Fe powders for food fortification concluded that electrolytic Fe was the only Fe powder to be recommended. On the basis of the change in body Fe stores during a 35-week study in Thai women, Zimmermann et al. ${ }^{(19)}$ verified that the relative efficacy of the electrolytic and $\mathrm{H}_{2}$-reduced Fe compared with $\mathrm{FeSO}_{4}(12 \mathrm{mg} \mathrm{Fe} / \mathrm{d}$ ) was $77 \%$ and $49 \%$, respectively. Nevertheless, two other studies using electrolytic Fe did not find improvement of Fe status ${ }^{(20,21)}$.

Special concern prevails for the use of Fe-fortified cereals $^{(8)}$. There exist two major disadvantages in the use of cereal products as vehicles for Fe fortification: (i) they contain high levels of phytic acid, a potential inhibitor of Fe absorption; and (ii) they are extremely sensitive to fat oxidation during storage when highly bioavailable $\mathrm{Fe}$ compounds such as $\mathrm{FeSO}_{4}$ are employed ${ }^{(22)}$. According to the International Nutritional Anemia Consultative Group $^{(23)}$, absorption of Fe is lower from maize than from other cereals. However, the type of cereal grain (rice, wheat, maize or oats) had shown little influence on Fe bioavailability in infant's cereals ${ }^{(24)}$. Furthermore, the processing methods used to reduce the content of phytate from cereals seemed more useful than the choice of a particular cereal grain ${ }^{(24)}$. The complete degradation of phytic acid in maize and other infant cereals increased Fe absorption by up to ten times ${ }^{(14)}$.

Table 1 Prevalence of blood parameter changes in Brazilian children and adolescents during 6 months of treatment with corn flour-derived products fortified with powdered elemental iron in the form of hydrogen-reduced iron

\begin{tabular}{|c|c|c|c|c|c|c|c|c|c|}
\hline & \multicolumn{8}{|c|}{ Assessments } & \multirow[b]{3}{*}{$P+$} \\
\hline & \multicolumn{2}{|c|}{$\begin{array}{l}\text { Altered first } \\
\text { and second }\end{array}$} & \multicolumn{2}{|c|}{$\begin{array}{l}\text { Altered first and } \\
\text { normal second }\end{array}$} & \multicolumn{2}{|c|}{$\begin{array}{l}\text { Normal first and } \\
\text { altered second }\end{array}$} & \multicolumn{2}{|c|}{$\begin{array}{l}\text { Normal first } \\
\text { and second }\end{array}$} & \\
\hline & $n$ & $\%$ & $n$ & $\%$ & $n$ & $\%$ & $n$ & $\%$ & \\
\hline $\mathrm{Hb}(\mathrm{g} / \mathrm{dl})$ & 29 & $17 \cdot 9$ & 13 & $8 \cdot 0$ & 19 & $11 \cdot 7$ & 101 & $62 \cdot 4$ & $0 \cdot 29$ \\
\hline Transferrin saturation (\%) & 5 & $3 \cdot 1$ & $23^{*}$ & $14 \cdot 2$ & 11 & $6 \cdot 8$ & 123 & $75 \cdot 9$ & 0.04 \\
\hline Ferritin $(\mu \mathrm{g} / \mathrm{l})$ & 9 & $5 \cdot 5$ & $20^{*}$ & $12 \cdot 4$ & \multicolumn{2}{|c|}{ No subject } & 133 & $82 \cdot 1$ & $<0.001$ \\
\hline
\end{tabular}

No subject $=$ no subject showed change.

* Statistically significant difference from altered first and normal second to normal first and altered second value assessments.

tMcNemar's test for paired data. 
Table 2 Comparison of blood parameter values in Brazilian children and adolescents at the beginning of the study and following 6 months of treatment with corn flour-derived products fortified with powdered elemental iron in the form of hydrogen-reduced iron

\begin{tabular}{|c|c|c|c|c|c|c|c|c|c|c|c|}
\hline \multirow[b]{2}{*}{ Blood parameter } & \multirow[b]{2}{*}{$n$} & \multicolumn{3}{|c|}{ Before fortification } & \multicolumn{3}{|c|}{ After fortification } & \multicolumn{3}{|c|}{ Paired difference } & \multirow[b]{2}{*}{$P+$} \\
\hline & & Mean & SD & Median & Mean & SD & Median & Mean & SD & Median & \\
\hline \multicolumn{12}{|l|}{$\mathrm{Hb}(\mathrm{g} / \mathrm{dl})$} \\
\hline Altered & 42 & $11 \cdot 5$ & 0.5 & $11 \cdot 6$ & $11 \cdot 6$ & 0.5 & $11 \cdot 7$ & $0 \cdot 17$ & 0.52 & 0.25 & \multirow[t]{2}{*}{$<0.001$} \\
\hline Normal & 120 & $12 \cdot 9$ & 0.5 & $12 \cdot 7$ & $12 \cdot 6$ & 0.6 & $12 \cdot 5$ & -0.26 & 0.59 & -0.20 & \\
\hline \multicolumn{12}{|c|}{ Transferrin saturation (\%) } \\
\hline Altered & 28 & $10 \cdot 9$ & $3 \cdot 8$ & $11 \cdot 7$ & $26 \cdot 4$ & $10 \cdot 9$ & $25 \cdot 2$ & $15 \cdot 46$ & $9 \cdot 75$ & $14 \cdot 49$ & \multirow[t]{2}{*}{$<0.001$} \\
\hline Normal & 134 & $28 \cdot 3$ & $8 \cdot 3$ & $26 \cdot 8$ & $30 \cdot 8$ & $12 \cdot 3$ & $29 \cdot 3$ & $2 \cdot 49$ & $12 \cdot 66$ & $1 \cdot 80$ & \\
\hline \multicolumn{12}{|l|}{ Ferritin $(\mu \mathrm{g} / \mathrm{l})$} \\
\hline Altered & 29 & $13 \cdot 2$ & $4 \cdot 1$ & $12 \cdot 7$ & $25 \cdot 5$ & $10 \cdot 8$ & $23 \cdot 3$ & $12 \cdot 32$ & $10 \cdot 88$ & $9 \cdot 38$ & \multirow[t]{2}{*}{$<0.001$} \\
\hline Normal & 133 & $41 \cdot 4$ & $15 \cdot 4$ & $38 \cdot 6$ & $45 \cdot 5$ & $18 \cdot 2$ & $42 \cdot 3$ & $4 \cdot 01$ & $13 \cdot 64$ & $2 \cdot 85$ & \\
\hline
\end{tabular}

tMann-Whitney test to compare the difference between normal and altered values.

Another issue that needs to be considered is that short-term studies ${ }^{(25)}$ and single meals ${ }^{(10,11)}$ seem to overestimate differences in dietary Fe bioavailability. Lind et al. $^{(26)}$ have not verified a greater effect on $\mathrm{Hb}$ or serum ferritin in a long-term study despite a $77 \%$ reduction in the daily phytate intake from infant's cereal.

The data of the present study show a decrease in ID and IDA from $18 \cdot 0 \%$ and $14 \cdot 9 \%$ to $5 \cdot 6 \%$ and $1 \cdot 2 \%$, respectively, after 6 months. This favourable response can be partially explained by the milling and degerming methods used to transform the cereal grain into corn flour, which are responsible for decreasing phytic acid found in the germ part of the grain ${ }^{(24)}$. Moreover, the Brazilian regional diet offered at lunch in the educational centres consisted of rice, bean and $50 \mathrm{~g}$ of meat; this may have contributed to the observed favourable results, although the children were eating the educational centres' diet for a long time before the beginning of the study.

Many studies have confirmed the enhancing effect of muscle tissue on Fe absorption ${ }^{(8,27,28)}$, counteracting the inhibition of non-haem absorption by phytate ${ }^{(9)}$. It was first shown 40 years ago that the addition of veal meat to a meal of black beans and maize doubled non-haem Fe absorption $^{(29)}$. Meat (20 g) has a non-haem Fe absorption factor from a typical wholegrain weaning meal of approximately $60 \%{ }^{(30)}$. The enhancing effect of meat on Fe absorption is known as the 'meat factor' or 'meat effect', and may be related to the potential ability of sulfhydryl-containing amino acids or peptides to chelate non-haem Fe, thereby facilitating its intestinal absorption ${ }^{(28)}$. In the present study, enhancing Fe absorption with ascorbic acid or its inhibition by tannins did not seem to play a role in the regional diet offered to the children.

Previous studies have reported the successful use of elemental electrolytic Fe to fortify wheat flour in Chile ${ }^{(12)}$; in contrast, increased ID from $39 \cdot 3 \%$ to $50 \cdot 4 \%$ was determined in 15- to 16-year-old Swedish girls ${ }^{(31)}$ following withdrawal of carbonyl-Fe fortification from flour.

It is conceivable that Fe fortification treatment for periods longer than 6 months could normalize serum ferritin levels of the remaining nine children showing low serum ferritin levels at the end of the present study. Hallberg stated that the main effects on Fe status of fortification by the administration of $\mathrm{Fe}$ or by improvement of dietary bioavailability are to be expected after about one year ${ }^{(2)}$.

Low cost is an important factor in the planning of public assistance programmes in underdeveloped and even in developed countries ${ }^{(12)}$. Although the utilization of corn flour as the vehicle and elemental Fe as the fortifier could be a reason for concern, this less expensive combined way of Fe fortification yielded a good response when part of a complete diet. Adequate processing methods of cereal flour fortified with sufficient doses of, and small size of the elemental Fe powder employed seem to be critically important for the good responses obtained in the present study.

To conclude, corn flour-derived products, fortified with reduced $\mathrm{Fe}$ administered during 6 months, significantly decreased the prevalence of ID and IDA in children and adolescents living in Londrina, Parana State, Brazil.

\section{Acknowledgements}

The material for the study was provided by Nutrimilho Ind. \& Com. de Alimentos, Ltd (Maringá, Paraná, Brazil). None of the authors had any personal or financial conflict of interest. L.H.S.M. was responsible for recruiting the patients, the original concept of the study, the study design, interpretation of the results and the writing of the manuscript. I.D. was responsible for the interpretation of the results and the writing of the manuscript. T.M. was responsible for the statistical analysis. J.B.D. was responsible for interpretation of the results and the writing of the manuscript. J.W.B. was responsible for the haematological assessment. D.S.B. was responsible for the biochemical assessment. The resources employed in the investigation were obtained from the Universidade Estadual de Londrina, which maintains reagents and facilities for laboratory training of students, and those obtained through the Official Agreements between the 
University and the company Nutrimilho, which obtains rebate of income taxes for supporting the institution in developing research.

\section{References}

1. Stolzfus RJ (2001) Defining iron-deficiency anemia in public health terms: a time for reflection. $J$ Nutr 131, 565S-567S

2. Hallberg L (2001) Perspectives on nutritional iron deficiency. Annu Rev Nutr 21, 1-21.

3. Grantham-McGregor S \& Ani C (2001) A review of studies on the effect of iron deficiency on cognitive development in children. J Nutr 131, 649S-668S.

4. Beard JL \& Connor JR (2003) Iron status and neural functioning. Annu Rev Nutr 23, 41-58.

5. Akman M, Cebeci D, Okur V, Angin H, Abali O \& Akman AC (2004) The effects of iron deficiency on infants' development test performance. Acta Paediatr 93, 1391-1396.

6. Konofal E, Lecendreux M, Arnulf I \& Mouren M-C (2004) Iron deficiency in children with attention-deficit/hyperactivity disorder. Arch Pediatr Adolesc Med 158, 1113-1115.

7. Bruner BA, Joffe A, Duggan AK, Casella JF \& Brandt J (1996) Randomised study of cognitive effects of iron supplementation in non-anaemic iron-deficient adolescent girls. Lancet 348, 992-996.

8. Hurrell RF (2002) Fortification: overcoming technical and practical barriers. J Nutr 132, 806S-812S.

9. Hallberg L (2002) Advantages and disadvantages of an ironrich diet. Eur J Clin Nutr 56, Suppl. 1, S12-S18.

10. Cook JD, Dassenko SA \& Lynch SR (1991) Assessment of the role of nonheme-iron availability in iron balance. Am J Clin Nutr 54, 717-722.

11. Cook JD \& Reddy MB (2001) Effect of ascorbic acid intake on nonheme-iron absorption from a complete diet. $A m J$ Clin Nutr 73, 93-98.

12. Walter T, Dallman PR, Pizarro F, Vebozo L, Peña G, Bartholmey SJ, Hertrampf E, Olivares M, Letelier A \& Arredondo M (1993) Effectiveness of iron-fortified infant cereal in prevention of iron deficiency anemia. Pediatrics 91, 976-982.

13. Miglioranza LHS, Matsuo T, Caballero-Córdoba GM, Dichi JB, Cyrino ES, Oliveira IBN, Martins MS, Polezer NM \& Dichi I (2003) Effect of long-term fortification of whey drink with ferrous bisglycinate on anemia prevalence in children and adolescents from deprived areas in Londrina, Paraná, Brazil. Nutrition 19, 419-421.

14. Hurrell R (2002) How to ensure adequate iron absorption from iron-fortified food. Nutr Rev 60, S7-S15.

15. Roe MA \& Fairwheather-Tait SJ (1999) High bioavailability of reduced iron added to UK flour. Lancet 353, 1938-1939.

16. García-Casal MN, Larysse $M$, Pena-Rosas JP, Ramirez J, Leets I \& Matus P (2003) Iron absorption from elemental iron-fortified corn flakes in humans. Role of vitamins A and C. Nutr Res 23, 451-463.
17. Walter T, Pizarro F, Boy E \& Abrams SA (2004) The poor bioavailability of elemental iron in corn masa flour is not affected by disodium EDTA. J Nutr 134, 380-383.

18. Hurrell R, Bothwell T, Cook JD et al. (2002) The usefulness of elemental iron for cereal flour fortification: a SUSTAIN Task Force report. Sharing United States Technology to Aid in the improvement of Nutrition. Nutr Rev 60, 391-406.

19. Zimmermann MB, Winichagoon P, Gowachirapant $S$, Hess SY, Harrington M, Chavasit V, Lynch SR \& Hurrell RF (2005) Comparison of the efficacy of wheat-based snacks fortified with ferrous sulfate, electrolytic iron, or hydrogen-reduced elemental iron: randomized, double-blind, controlled trial in Thai women. Am J Clin Nutr 82, 1276-1282.

20. Andang'o PEA, Osendarp SJM, Ayah R, West CE, Mwaniki DL, De Wolf CA, Kraaijenhagen R, Kok FJ \& Verhoef H (2007) Efficacy of iron-fortified whole maize flour on iron status of schoolchildren in Kenya: a randomized controlled trial. Lancet 369, 1799-1806.

21. Nestel P, Nalubola R, Sivakaneshan R, Wickramasinghe AR, Atukorala S, Wickramanaye $\mathrm{T} \&$ the Flour Fortification Trial Team (2004) The use of iron-fortified wheat flour to reduce anemia among the estate population in Sri Lanka. Int J Vitam Nutr Res 74, 35-51.

22. Hurrell R (1997) Preventing iron deficiency through food fortification. Nutr Rev 55, 210-222.

23. International Nutritional Anemia Consultative Group (1982) The Effects of Cereals and Legumes on Iron Availability. Report of INACG. Washington, DC: The Nutrition Foundation.

24. Cook JD, Reddy MB, Burri J, Juillerat MA \& Hurrell RF (1997) The influence of different cereal grains on iron absorption from infant cereal foods. Am J Clin Nutr 65, 964-969.

25. Hunt JR \& Roughead ZK (2000) Adaptation of iron absorption in men consuming diets with high or low iron bioavailability. Am J Clin Nutr 71, 94-102.

26. Lind T, Lönnerdall B, Persson L-A, Stenlund H, Tennefors C \& Hernell O (2003) Effects of weaning cereals with different phytate contents on hemoglobin, iron stores, and serum zinc: a randomized intervention in infants from 6 to 12 mo of age. Am J Clin Nutr 78, 168-175.

27. Engelmann MDM, Sandström B \& Michaelsen KF (1998) Meat intake and iron status in late infancy: an intervention study. J Pediatr Gastroenterol Nutr 26, 26-33.

28. Baech SB, Hansen M, Bukhave K, Jensen M, Sorensen SS, Kristensen L, Purslow PP, Skibsted L \& Sandström B (2003) Nonheme-iron absorption from a phytate-rich meal is increased by the addition of small amounts of pork meat. Am J Clin Nutr 77, 173-179.

29. Hurrell RF (1997) Bioavailability of iron. Eur J Clin Nutr 51 , Suppl. 1, S4-S8.

30. Hallberg L \& Hulthén L (2002) Perspectives on iron absorption. Blood Cells Mol Dis 29, 562-573.

31. Hulthén L \& Hallberg L (2004) Increased prevalence of iron deficiency due to withdrawal of iron fortification of flour in Sweden. In Report of the 2004 International Nutritional Anemia Consultative Group Symposium, Lima, Peru, 18 November 2004, p. 63. Washington, DC: INACG. 